\title{
Do You Understand Our Understanding? Personas as Hermeneutic Tools in Social Technology Projects
}

\author{
Natalie Hardwicke \\ Discipline of Business Information Systems \\ The University of Sydney Business School \\ Sydney, New South Wales, Australia
}

\section{Kai Riemer}

Discipline of Business Information Systems

The University of Sydney Business School

Sydney, New South Wales, Australia

Email: kai.riemer@sydney.edu.au

\begin{abstract}
Personas, prevalent in information systems design and implementation, are often positioned as aesthetic creations imitating technology "end users". As such, there is an inherent assumption that end user outcomes can be known prior to technology usage in practice. This assumption, however, becomes problematic in malleable end user software (MEUS) contexts, in which concrete usage is unknowable a priori. Through an auto-ethnographic account of a unique case of a small consultancy, the Ripple Effect Group, attuned to the nature of MEUS, we explore a novel approach to personas in social technology projects. We turn to the work of Gadamer (1975) to outline two distinct views of "mimesis" for contrasting the dominant portrayal of personas in the literature compared to our empirical context. Our paper challenges conventional thinking surrounding personas, and offers a practical approach, and preliminary theorizing, for personas as hermeneutic tools to convey meaning for those involved in MEUS projects.
\end{abstract}

Keywords: personas, hermeneutics, mimesis, malleable technology, enterprise social networking 


\section{Introduction}

The use and exploration of "personas" in information systems (IS) has been evident, according to Clarke (2014), for more than two decades. These archetypes, created as either fictitious characters or as representations of real people, are predominately viewed as depicting the potential, or intended, end users of a technological system (Dittmar and Hensch 2015). The premise behind personas is that they help capture the various goals, motivations, and behaviours different end users will have towards a particular product or service (Dotan et. al 2009). In this regard, personas are seen as creative artefacts (Hussain and Skillicorn 2008) that are purposefully crafted to help keep the real or imagined end users "in mind" throughout system design phases. The belief, in doing so, is that personas help designers create a product that will be a technological success with its real-life end users.

Despite, however, the positive intent of wanting to design for a real or imagined person, such an approach towards personas and systems design often presents a clear demarcation between user and technology. This means that an inherent assumption is being made in which a technological outcome can be pre-determined, and user interaction understood, prior to technology use taking place inpractice. In this paper, we explore how personas are portrayed in this manner in an IS context, and then problematize such assumptions with regard to the following.

Firstly, the dominant view of personas as representing end user technology outcomes becomes challenged in contexts involving malleable end user software (MEUS) (Richter and Riemer 2013). Even if MEUS are designed with the end user in mind, the meaning the technology will come to have with end users can arguably not be known until usage takes place. Secondly, we as the two authors of this paper have had, for a number of years, a relationship with the Ripple Effect Group (REG). As social business designers, REG specialise in connecting people with technology inside workplace contexts, working with clients who want their workforce to "use" enterprise social networking (ESN), a type of MEUS. In each client project, REG state that their main deliverable will be the creation of what they call "authentic personas". However, the REG personas are not intended for a technological usage outcome. Rather, the role of such personas is to aid in sense-making and understanding of the world of the "user".

In exploring the REG personas, the aim of our paper is to therefore challenge conventional wisdom of persona creation and use in IS (Alvesson and Kärreman 2007). We firstly draw upon Gadamer's (1975) view of "mimesis" to explore two different interpretations of personas as creative artefacts. In the first view, personas can be seen as imitations of, or substitutes for, real people, whilst in the second view, personas can be seen as a hermeneutic act, creations intended for interpretation and understanding. Through the mimetic lens, we discuss how personas are portrayed in IS and challenge such views in relation to MEUS. In providing an auto-ethnographic account of the REG practice, our paper foregrounds preliminary theorizing for personas as vehicles for understanding, rather than as mechanisms for achieving a technological end. We stipulate that this hermeneutic persona approach can become useful for conveying meaning about end user realities regarding malleable technology.

\section{Personas as a Mimetic Act}

The word "persona" stems from Latin origins relating to the word "mask", in which actors in Ancient Greece and Rome would perform on a stage and their worn masks would function as a resonance chamber for sound to be amplified through (Hopcke 1995). In modern times, personas have been used across multiple contexts, becoming aesthetic substitutes for real people (e.g. Grudin 2006). This can include online gaming avatars (e.g. Schultze et. al 2007), characters of digital brands (e.g. Herskovitz and Crystal 2010), or as anticipated users, created to aid technology design (e.g. Mulder and Yaar 2006).

In the technology context, personas are created as communicative artefacts, described as illustrations of targeted end users. These created characters are often accompanied with journey maps and story boards to demonstrate how a persona, or a cast of personas, would likely act in relation to a certain scenario or hypothetical narrative involving technology (Long 2009). The overall purpose of personas is that they are said to help disseminate an understanding, to all members of a design team, about end user needs in creating technological solutions for those end users (Pruitt and Grudin 2003).

What is evident, however, throughout such depictions of personas, are conflicting views about what role these created characters actually come to play. To explore different interpretations, we found it useful to turn to Gadamer's (1975) work on philosophical hermeneutics. In his work, Gadamer explores two conflicting views of "mimesis" in relation to artistic creations, of which personas can be viewed as one example. In the most literal interpretation, mimesis is viewed as an act of imitation. Personas, in this view, would be seen as substitutes, or "stand-ins" for real people, and become blueprints intended to elicit an outcome for the people whom they are said to represent. In such an understanding, implicit 
emphasis is placed on the notion that end users of a technology can be known, their factual properties be captured, and technology by made to "fit". Although it is acknowledged that a difference exists between what is the original and what is a "copy", the artistic copy is still viewed as capturing knowledge of the original essence. In turn, the created artefacts are seen as portraying an objective view of reality, conveying such a reality to an audience through an aesthetic outlet and an accompanying narrative. As such, personas become a vehicle for communicating in accessible and aesthetically pleasing ways.

In the alternate view, aligned with Gadamer's own position, mimesis is seen as a phenomenological act in its own right. The created personas would be seen not as imitating an objective reality, but as being a creation to foreground a lived experience. The hermeneutic view of mimesis is the idea that what is created, such as personas, allows for an audience to enter into a disclosed world. For example, actors on a stage performing their roles, much like personas and their narratives, need an audience to bring the world of the characters to life. In this view, the characters have their stories to tell, and the action they take in telling their story is something the audience cannot control, or know the outcome. However, the audience are free to interpret, for themselves, the story's meaning.

What this hermeneutic approach offers, which the imitative view does not, is the opportunity for a difference in outcome. In Gadamer's view, it is important for the audience to understand what the story means for themselves, as this meaning is what elicits change in the audience. In the persona context, it would not be about the audience understanding factual realities about "user" and "technology", but about the questioning of possibility for what the persona narrative discloses. This idea aligns to persona origins in Greek plays, in which the performance of actors wearing masks was not intended to be a portrayal about the actors, but for the disguise as being necessary for audiences to induce meaning about the performance for themselves (Hopcke 1995).

In the following, we use both views of mimesis as a lens for exploring how personas have been depicted in an IS context. Although we do not purport to give a complete analysis of all persona cases evident in the literature, we have sought to explore how and why personas emerged in IS, and the dominant role they are seen as having in relation to technology; specifically software design and its usage.

\section{Personas in Information Systems (IS)}

In business, personas are said to have originated in marketing with a focus on customers as targeted demographics (e.g. Sissors 1966). Later, these roles were reversed in which consumer insights came first and personas were created to help guide marketing decision-making (Upshaw 1995). For IS specifically, personas have been re-imagined from their marketing origins to serve as a theoretical underpinning to "design thinking" in systems design processes (Cooper 1999). What this persona underpinning achieved was an ability to represent technology end users in a more realistic manner (Mulder and Yaar 2006).

The reason for this was seen as a result of the limitations associated with previous approaches, in which end users were often abstracted or omitted from systems design activities. For example, scenario planning was often used based on a task-fit logic; one which aimed to dictate computer interaction, rather than explore current contexts of targeted end user behaviour (Carroll 1995). Other examples of user profiles (Hackos and Reddish 1998), user roles (Constantine 2006) and user archetypes (Mikkelson and Lee 2000) followed a similar mode of thinking, as software was often designed based on abstractions made about intended users, whilst technological goals remained front and centre. This persona shift has been noted for making designed products or services more successful, as the design serves the needs of users rather than satisfy the goals of designers (Abras et al. 2004).

Accordingly, personas have been positioned as tools to help combat issues associated with IS utility and systems failure outcomes (Brickey et al. 2012); based on the premise that personas can be substitutes for real end users. What is also evident, however, are the two beliefs associated with the conflicting views of mimesis; of whether personas are in fact imitations of users, or whether the personas are meaningful interpretations in their own right, with the ability to help designers in their systems design processes.

\subsection{Representing End Users or Tools for Designers?}

In contrast to earlier methods, personas were seen as offering a more realistic approach to understanding end users, achieved through the capturing of actual user insights as collated from various data sources. Originally, personas were an ethnographic endeavour comprising of qualitative approaches of participant observation and interviews (Cooper et. al 2007). However, multiple data gathering methods for persona creation have since been articulated. Mulder and Yaar (2006) even argue that both qualitative and quantitative measures should be used, with types ranging from surveys and 
market research reports (Pruitt and Grudin 2003), user diaries (Kantola et. al 2007), job profiles (O'Flaherty et al. 2013), or even capturing existing log data from in-use systems (Mesgari et. al 2015).

The emphasis on data collected about end user behaviour, and user activities, can be interpreted as a desire to represent the "object" of the end user. What is indicative in such data approaches is the focus on capturing factual or historical data about what end users do and say. Minimal attention is given to understanding the "lived world" of an end user or what they do or think beyond factors associated with their "role". Arguably, if personas were in fact intended to represent end users, one could assume that end users would be able to comment, or provide feedback on, the personas made in their image. This, however, does not seem to occur. Instead, personas are positioned as being meaningful for the designers. For example, personas are often used as communication devices during brainstorming sessions (Jansen et. al 2013), as artefacts to help guide or inform decision-making, or as an avenue to help test and evaluate aspects of user and task performance on the designed system (Pruitt and Adlin 2006).

Furthermore, emphasis is firmly on systems design rather than the holistic use context, despite the fact end user challenges exist beyond a technology's design; such as problems associated with the technology's introduction and integration with existing work and infrastructure (Chapman and Milham 2006). What this means is that although personas might be created based on the assumption of portraying end users, their use seems to be specific to the work of designers in system creation processes.

Interestingly, one ethnographic study noted that despite the effort put into creating personas, one team's personas did not play a direct role in the decision-making for the technology being designed (Friess 2012). This does not necessarily indicate anything specific about the personas, the technology in question, or the intended end users, but instead brings to the fore issues concerning the relationship and the differences between personas and real people. In such examples, Turner et. al (2014) implies that the mere presence of personas might simply serve as scenario-planning instigators - allowing designers to pretend or imagine the "what ifs" of the system they are trying to design for "real world" application.

What this establishes is contemplation for whether personas are really about representing end users, or whether they are merely another tool in a designer's arsenal. However, the view of personas as being imitations of actual end users seems to be the favoured approach. In fact, according to Miaskiewicz and Kozar (2011), personas are seen as suffering from a lack of empirical grounding, as variances in method for their creation and use are evident across examples; implying that these are the reasons why persona theorising is difficult. It therefore seems necessary to explore the different persona types, for which Nielsen (2013) claims there are four as being evident across influential works.

\subsection{Persona Types and Intended Outcomes}

Although personas can be created with or without end user data, the number of personas created, the content that is included in them, and the narratives that take the persona characters on a journey, are all seen as being to the detriment of the design team (Nielsen 2013). This can include, depending on the lifetime of the project, the need to revise personas to ensure they are still "relevant" based on any end user changes. However, in outlining the four most prominent persona types, it is clear that their focus aligns to capturing the characteristics of both users and technology. In the first goal-oriented type, personas focus on supporting users in achieving their goals on or with a particular technology (e.g. Cooper 1999). For example, one case used personas in designing driver assistance systems, such as cruise control and parking assist, relative to different (persona) driving types (Lindgren et. al 2007).

As a second approach, role-based personas focus on an end user's position (role) in a social or an organisational context (e.g. Pruitt and Grudin 2003). For example, a predictive analytics cloud service application depicted personas as representing different user roles which were indicative of business goals associated with employee job types (O'Flaherty et. al 2013). In the third approach, personas can be seen as "engaging" creations, ones which emphasise the narrative story that helps designers understand the traits of targeted end users, either via a narrative created by designers, or by data being captured that allows end users to tell their own story. Lastly, there are also fictitious personas, created as imagined or targeted end users, often without any formalised data process involved (Pruitt and Adlin 2006). However, such fictitious characters are still seen as helping to design for "someone" in mind.

What all four examples do is present a dualism between technology and end users; implying that characteristics of end users can be captured and matched with characteristics of technology. In this vein, personas as imitative acts seem to be the dominant stance, as personas are depicting "users" who are intended to "use" technology as it has been designed for them. Where this dominant imitation view comes unstuck, we argue, is in relation to malleable end user software (MEUS). 


\section{Problematizing Personas in relation to MEUS}

Compared to more purpose-specific end user software (PEUS), the use and application of MEUS is indicative of social processes, rather than technological features (Richter and Riemer 2013). The malleability of the technology means that usage cannot be known a priori, and any intended usage outcomes will likely deviate given the often social and interactive nature of such technologies (Dourish 2003). Even in PEUS contexts, usage in-practice has still been known to deviate from intended end user interaction (e.g. Arvidsson et. al 2014). Reasons for this are often explored from a social practice perspective, in which end users will still need to find a way to integrate new technology into their existing practices (Visconti 2010). Despite how the technology has been designed and for what purpose, usage becomes context dependent, as not all technological "features" will be relevant to all users.

Discussions concerning the people and technology relationship have been ongoing in IS for many years. Two dominant ontologies are seen to be at play (e.g. Riemer and Johnston 2014); one which supports the dualism between people and technology, and one which supports their inseparability. Although such an exploration is beyond the scope of this paper, the two views of mimesis also align to such distinctions. The imitative form clearly separates persona from technology usage, whilst the hermeneutic stance sees the act of persona creation as something that already constitutes a people-technology inseparability; as already in-use technologies are inseparable from, and form an integral part, of their respective persona.

Where this hermeneutic view makes more sense, in relation to personas and end user outcomes, can be seen with enterprise social networking (ESN) platforms. As a type of MEUS, a platform's success is seen as being highly context-dependent in its usage with end users. The same ESN, for example, can be introduced in two different organisational settings and yet have very different usage outcomes (Mettler and Winter 2016). End users are seen as having to make sense, for themselves, of what role this technology will play in their work. The voluntary nature of ESN means that its purpose is specific to users, and its success is driven by them (Kumar et. al 2016). Although technological design might play a role with usage, such features like "blog" or "wiki" do not automatically dictate what will be published on the platform, or who will engage with content (Dix 2007). In translation, neither end users nor designers can know what outcomes or purposes social technology will result in until usage takes place.

If anything, the design of social technology is what allows for this unexpected usage to take place, as the malleability means that usage can be reimagined over time and contexts. For example, the notion of secondary design has been discussed in tailorable technology examples (e.g. Germonprez et. al 2011), in which end user participation on a designed system can still result in changes to how the system functions, which in turn influences how content on that system becomes created and perceived by users. These types of observations were not foreseen or pre-empted by designers. What this suggests is that given the dominant portrayal of personas as being tools for achieving a technological outcome, and MEUS cannot have its end user outcome known a priori, the presence of personas in MEUS contexts offers a mystery to be explored (Alvesson and Kärreman 2007). In the following, we outline such a case.

\section{The Ripple Effect Group (REG)}

The Ripple Effect Group (REG) are a Sydney-based consultancy who specialise in connecting people with technology; predominately in digital workplace contexts. In taking a user-centred design approach, REG work with a variety of client organisations predominately on projects concerning MEUS. This can be in relation to technology implementation, designing solutions for community management of such software, or helping to address problems relating to MEUS use and integration within organisations. The REG Managing Director has had a long-standing relationship within our University context, for which the first author has an embedded relationship with their practice. In the following, an autoethnographic account is given by the first author in this role.

\subsection{Auto-ethnography of the REG Practice}

I have been "embedded" in the REG practice since March 2016. Originally used in journalistic settings (McGinity and Salokangas 2014), researcher embeddedness is an approach for exploring empirical practices in an ethnographic capacity. This means I play a dual practitioner-researcher role with REG in that I act as a "consultant" when I accompany them on client projects, and then act in the role of "researcher" when in-house. What this dual role has allowed me to do is learn the REG practice through a process of "doing", as well as learn about the issues and problems REG practitioners face across their client projects (Hardwicke 2017). Since my commencement, I have accompanied REG across several different client projects. Furthermore, as a result of being embedded, I have access to the REG internal 
systems. This means that any work conducted by REG during or prior to my engagement with them is stored on their systems, which I am able to access and inquire about at any time.

In each of the client projects I have been involved with, REG have enacted their "Head Start" method. This is a framework that helps guide clients through the intended approach REG will take for engaging with the client's workforce. In such projects, the clients have come from enabling business functions, such as human resources. Such functions have the benefit of being aligned to senior management and have visibility of their organisation's breadth. In each project, the client wanted their employees "communicating and collaborating" on ESN, yet in all cases, REG stated that their main contribution would be the creation of "authentic personas"; presented as a cast of six. The justification for this number is based on a soap opera analogy. Clients are encouraged to think of their favourite television show and its main characters - the idea being that the world the show is situated in, and the supplementary characters who comprise that world, are brought to life through the lens of the six as the main cast.

In order to foreground the REG persona approach, generic processes will be discussed in the following sections. This is in terms of how data is collected, interpreted, and transformed into the cast of personas. Of course, in providing an auto-ethnographic account, my own interpretation comes to the fore in how I have arrived at my understanding of the REG persona process and the intent behind their creation and use. However, given my embedded involvement, my understanding of personas has been the result of a longitudinal and ethnographic relationship with the REG practitioners. What this has meant is that my understanding is the result of being involved in these persona projects, and being able to ask, in-house, what is being done and why; including permission and feedback in writing this very paper.

\subsection{Data Collection Processes}

The REG Head Start method comprises two phases. The first phase includes initial project management and scope meetings with the client practice, which is then followed with preliminary engagements with the client's organisational employees. The initial project meetings help the REG practitioners learn about the client's problem and what they hope to achieve by engaging the REG practice. The client practice is also responsible for arranging access to organisational employees for the REG practitioners to engage with. REG seek to meet and speak with a range of employees from different departments in order to learn what the organisation looks like from different employee perspectives. As part of phase one, REG conduct interviews, site visits, and workshops with such employees. The questions that are asked in interviews, and the activities conducted in workshops, often relate to aspects of what the client hopes to achieve - to gauge how employees perceive the same organisational problem as the client does.

Insights captured from these first phase activities then aid in helping the REG practitioners come to an emerging understanding about the various points of view that exist across the organisation, and to make sense of the organisational culture. A debrief report about this phase is given to the client practice to disclose emerging themes, as well as to outline phase two. In phase two, more designed-focus activities take place in workshops and webinars. This can include "draw your metaphorical workplace", card sorting activities in which participants choose, and then discuss, which five words best describe their organisation, as well as participants getting into groups and crafting their own raw persona. These personas are then transformed into medium-fidelity versions by the REG practitioners (Figure 1), which are then presented to the client practice for feedback.
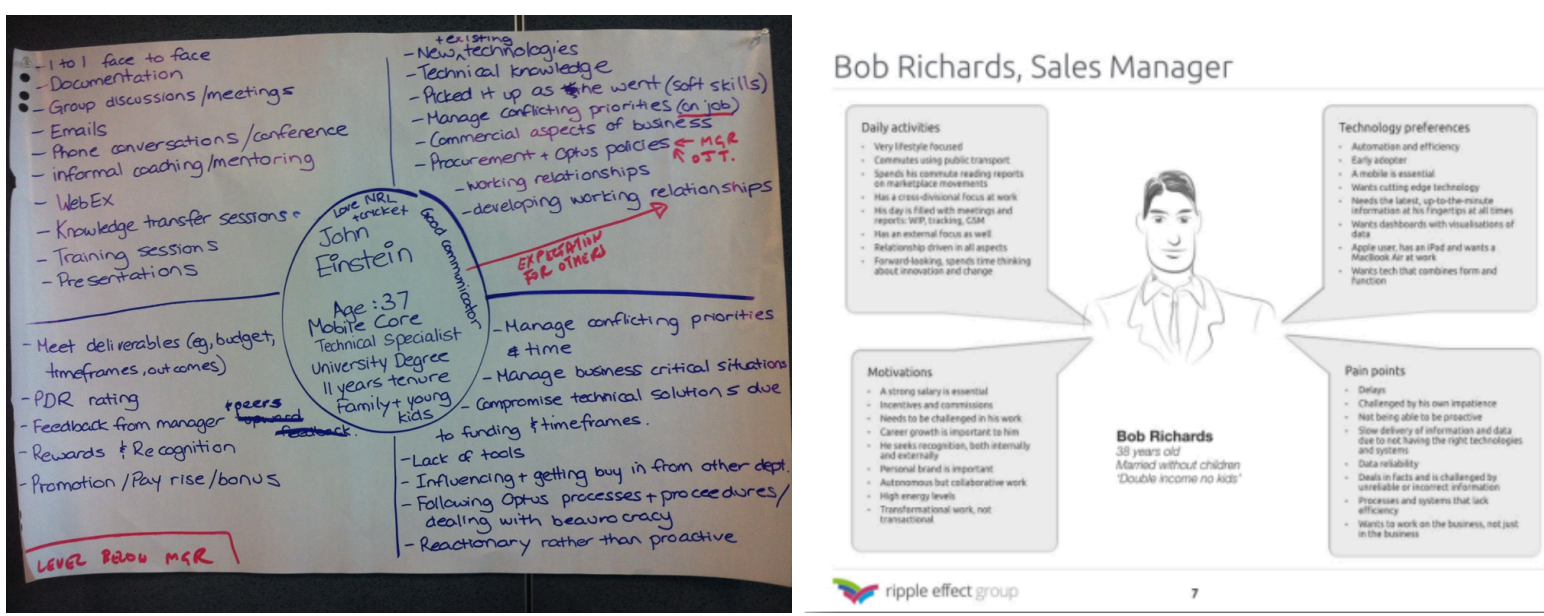

Figure 1: Raw and medium-fidelity persona examples (figure courtesy of The Ripple Effect Group) 


\subsection{The Role of Feedback}

The presented draft personas represent how REG have interpreted key characters based on their amalgamated experience with, and their interpretation of, employee insights. The draft personas are presented to the client as a validation process prior to personas being finalised. In these validation workshops, REG say to their client, "This is what we have learnt, does this sound right?" This simple prompt encourages the client practice to interpret the presented personas for themselves and their own working practice. This can also mean that client members ask about any information that might be missing from personas, inquire about insights captured, or make a number of comments and questions relating to what is portrayed about each persona.

This feedback is important for two primary reasons. Firstly, and as previously mentioned, the client practice has the benefit of organisational breadth; meaning they are expected to "know" who the organisation's employees are, what these employees do, and the tools and systems these employees work with. However, what is often presented to clients via feedback can be new information to them. For example, in one case, the client was shocked to learn that employees were already using shadow IT for their social networking purposes. In another case, the client saw the draft personas as missing a key demographic that needed to be captured. In such contexts, feedback becomes necessary for ensuring certain aspects of the organisation are represented through the cast of six personas.

The second reason for this feedback process is to instigate learning and reflection for the client practice themselves. Although they are positioned as being an enabling business function for their organisation, often what the REG practitioners present can seem new or surprising to the client practice. In this vein, the feedback can prompt them to reflect on their practices in order to better understand the targeted "end users" they are trying to make communicate and collaborate with one another. After this feedback process, the REG practitioners finalise the personas and create their six-character high-fidelity persona deck. User journey stories, or created narratives, are written for each persona (Figure 2).

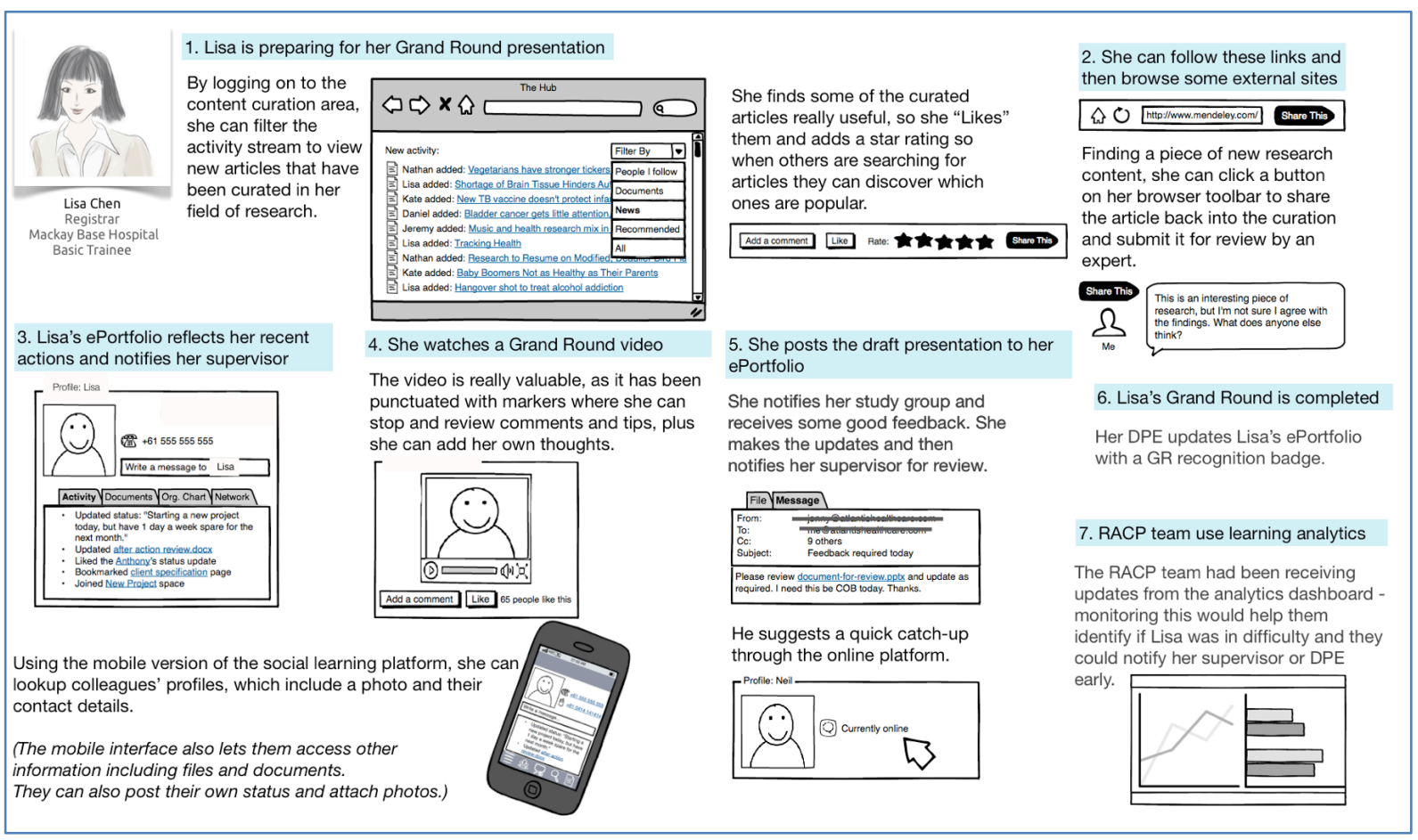

Figure 2: Example of a persona and their story

(figure courtesy of The Ripple Effect Group)

Personas themselves portray such things as background information regarding personal life, goals and motivations, in-use devices, resources, the people in their broader network, and attitudes towards technology. The stories crafted for each persona are intended to demonstrate how different employees interact and share content; the idea being that by understanding each persona the client practice can gain a sense of empathy for their organisational employees. Technology recommendations then accompany the personas, which are positioned towards the client practice - of how they can better enable employees in the context of what currently is versus what could be in the digital workplace. 


\subsection{Personas and Technology}

In addition to the work REG do with the client practice and organisational employees, a technology review also takes place. The REG practitioners will liaise with their client's IT representative, and in turn learn about current tools and systems in place. What this enables REG to do is make IT assumptions, and understand constraints, for what they can recommend to their client. However, such recommendations are not intended to be about implementing or imposing technology onto end user employees. Instead, the personas are used as the justification for REG practitioners outlining what the client practice needs to do to better support employees in their current communication and collaboration activities, for which in-use technologies are already evident, but for which future systems could be possible, or already planned by IT.

In more recent client contexts, future state scenarios have also been created, which have showcased how the cast of personas would likely interact and correspond to initiatives as instigated by the client practice enacting such recommendations. The group stories, presented as future-state scenarios, portray how the personas might act as a result of new technology, such as an ESN platform, being present inside the organisation. However, instead of depicting how personas would "use" such technology, the scenarios focus on potential outcomes, such as how personas might change to incorporate this technology into their working practice, and what the client practice could do to support such change.

The future state narratives are used to convey what "could be" as a result of the client practice changing. In such projects where the introduction of an ESN platform is considered, REG will position it to the client practice as a framework for consideration, outlining how technical aspects need to be considered, but that the platform itself needs to be understand from the stance of how personas (employees) will likely come to network and engage with one another both on and off the platform. Therefore, such recommendations are not about imposing technology onto "end users", but are more often about developing the digital knowledge and capabilities of the client practice; demonstrating how their own changes can empower the employees they work to enable.

\section{Analysis: What REG's use of personas reveals}

What is evident, in the REG personas, is that they share many similarities and characteristics with the personas portrayed in the IS literature. However, there are some fundamental differences, which we will explore in relation to three key deviations.

The first deviation lies in how the personas are created, including the data that is captured and the role of feedback. Unlike traditional persona approaches, as evident in the literature, the REG practitioners conduct certain activities as a way to get client employees to reveal insights about themselves and their organisation. The first phase of the Head Start method helps the REG practitioners make sense of the client and the organisational context they work in. This includes gauging perceptions for how different employees perceive the client's communication and collaboration problem. In this approach, the emphasis is not about "capturing" data or insights about end users, but is about REG learning about their client and the context they work in.

It is then through the more design-focused second phase activities that "data" is captured for personas. However, this again is not about capturing the factual properties or behaviours of employees as end users of technology. Instead, by getting employees to design their own personas, or by having them draw and discuss their metaphorical workplace, what is conveyed reveals current attitudes and perceptions, allowing employees to express their frustrations and desires about their current working lives. Such insights are captured, but are then interpreted, by the REG practitioners. This interpretation is expressed via their creation of medium-fidelity personas, which are presented to the client for their own learning and reflection. What is emphasised here is the focus on understanding and developing shared meaning for organisational perceptions, rather than capturing end user characteristics.

This then foregrounds the second area in which the REG personas deviate from established persona norms, which concerns multiple interpretations being embraced. Although clients initially come to REG with a problem in mind, which they want solved with social technology, the client problem itself becomes problematized as the REG method unfolds. Throughout the various activities and engagements REG undertake, including IT assessments, different employee "worlds" emerge (Riemer and Johnston 2017). What is meant by this is that depending on where employees work, and the work they do, different technologies are seen to be in-use; along with different attitudes and perceptions about the organisation. What this means for social technology specifically, as REG still need to deliver on their contractual obligation, is that the emphasis is not on a specific platform or technology solution. Instead, persona 
narratives embrace the organisation at the here-and-now, and technological change is viewed as something integrated into existing employee worlds.

Such an approach arguably aligns with the nature of social technology. The personas are not intended to be positioned to the client practice as a way that tells them how they can get their "end user" employees "using" social technology. Instead, the personas are positioned to the client as a way for them to understand the employee-technology relationship. The idea that is portrayed to the client is that they can become "community managers" for supporting the different ways employees work, rather than imposing a work style or a technology onto employees. This organic approach in enabling the client foregrounds the third persona distinction; which concerns the intent behind the personas.

Unlike traditional personas, which are intended to help systems designers achieve a technological end, the REG personas are firmly positioned towards their client's learning, and the client themselves as needing to change; not the organisation's employees. This is achieved by REG creating personas and their narratives, via various processes of interpretation, with the final product presented back to the client. The client must then interpret, for themselves, what REG have interpreted as expressed in their final persona deck and accompanying group story. A double hermeneutic process can thus be observed, for which referral back to Gadamer's (1975) hermeneutic view of mimesis becomes relevant.

\section{Discussion: Personas as Hermeneutic Representations}

The collective narrative story that a cast of personas tells can be viewed as a performance; one which encourages the client group, as the audience, to reflect on the conceptions behind the performance (Gadamer 1975). As the narrative persona story is being told to the client, the focus shifts away from a people-technology emphasis, and instead moves towards interpretation for the client group. Gadamer discusses this in the context of a story as moving its characters, for which any subject-object (usertechnology) distinction becomes obsolete, as the entangled world of the story is brought to life as the audience encounter and interpret the story's holistic unfolding.

In the REG-client context, each persona is their own character, yet it is only because of the relationship personas have with each other, as part of their shared story, that any meaning from the characters (personas) can be interpreted. This shifts away from personas as imitating reality, and instead moves towards personas as enabling hermeneutic reflection; in which the client's problem, of wanting to have employees "communicate and collaborate", is transformed as its assumptions are re-evaluated. As Gadamer puts it, the message that is conveyed via the performance of characters is a message not explicitly stated. The personas are not being positioned to the client group as a way that tells them how they can get their employees to "use" social technology, but are instead about conveying meaning to the client through a creative disguise; a meaning concerning a reinterpretation of employee worlds, as the interpretation relates to the client group and their re-examination of their original request.

Therefore, what a hermeneutic view on personas offers is something different from both a practical and theoretical stance. From a practical perspective, the REG authentic personas do not seek to capture employee realities, but instead acknowledge, and seek to understand, the different employee worlds as they are experienced and interpreted. This is necessary in relation to MEUS, as its usage reflects social processes, and the malleability of the technology means it can be reimagined and used in unexpected ways; making the emphasis of positioning the personas to the client as a way for the client to support such flux. From the theoretical perspective, personas and their stories enable interpretation of technology inseparability. Each persona embodies an existing technology relationship, and the shared story the personas tell conveys an enmeshed context. What can be inferred from this are personas as a question of meaning; one that is specific to both time and context. It is a meaning intended to instil learning and reflection about technology, rather than achieve a technological end, by the client group.

\section{Conclusion}

What we have foregrounded in this paper invites the need for different theorizing towards personas in information systems contexts. By using mimesis as a lens, we have discussed how personas can become tools for interpretation and understanding, rather than mere imitations of real or targeted technology end users. In this vein, what a hermeneutic approach of personas offers, compared to conventional persona wisdom, is an emphasis on interpretation and meaningful reflection. This, we argue, is necessary in social technology contexts in order to embrace the different worlds of people who need to find meaning and purpose for the technology for themselves, rather than have a technology solution imposed onto them as mere "users". 


\section{References}

Abras, C., Maloney-Krichmar, D., and Preece, J. 2004. "User-Centered Design," in Encyclopedia of Human-Computer Interaction, pp. 763-767.

Alvesson, M. and Kärreman, D. 2007. "Constructing mystery: Empirical matters in theory development," Academy of management review, 32(4), pp.1265-1281.

Arvidsson, V., Holmström, J. and Lyytinen, K., 2014. "Information systems use as strategy practice: A multi-dimensional view of strategic information system implementation and use," The Journal of Strategic Information Systems, 23(1), pp.45-61.

Brickey, J., Walczak, S., and Burgess, T. 2012. "Comparing Semi-Automated Clustering Methods for Persona Development,” IEEE Transactions on Software Engineering, (38:3), pp. 537-546.

Carroll, J. M. 1995. Scenario-Based Design: Envisioning Work and Technology in System Development, Hoboken, NJ, USA: Wiley Publishing.

Chapman, C. N., and Milham, R. P. 2006. "The Personas' New Clothes: Methodological and Practical Arguments against a Popular Method," in Proceedings of the Human Factors and Ergonomics Society 5oth Annual Meeting, San Francisco, CA, USA, pp. 634-636.

Clarke, R. 2014. "Persona missing, feared drowned: the digital persona concept, two decades," Information Technology \& People, 27 (2), pp.182-207.

Constantine, L. 2006. "User, Roles, and Personas," in The Persona Lifecycle: Keeping People in Mind Throughout Product Design, J. Pruitt and T. Adlin (eds.), San Francisco, CA, USA: Morgan Kaufman Publishers, pp. 498-519.

Cooper, A. 1999. The Inmates Are Running the Asylum: Why High-Tech Products Drive Us Crazy and How to Restore the Sanity, Carmel, IN, USA: Sams Publishing.

Cooper, A., Reinmann, R., and Cronin, D. 2007. About Face 3: The Essentials of Interaction Design, Indianapolis, IN, USA: Wiley Publishing.

Dittmar, A., and Hensch, M. 2015. "Two-Level Personas for Nested Design Spaces," in Proceedings of the 33rd ACM Conference on Human Factors in Computing Systems, pp. 3265-3274.

Dix, A. 2007. "Designing for appropriation," In Proceedings of the 21st British HCI Group Annual Conference on People and Computers: HCI, Volume 2 (pp. 27-30). British Computer Society.

Dotan, A., Maiden, N., Lichtner, V. and Germanovich, L. 2009. "Designing with only four people in mind. A Case Study of Using Personas to Redesign a Work-Integrated Learning Support System," Proceedings of the 12th IFIP TC, 13, pp.24-28.

Dourish, P. 2003. "The Appropriation of Interactive Technologies: Some Lessons from Placeless Documents," Computer Supported Cooperative Work (CSCW), vol. 12, no. 4, pp. 465-490.

Friess, E. 2012. "Personas and decision making in the design process: an ethnographic case study," In Proceedings of the SIGCHI Conference on Human Factors in Computing Systems, (pp. 12091218). ACM.

Gadamer, H.G. 1975. Truth and Method, trans. Garrett Barden and John Cumming. New York: Crossroad.

Germonprez, M., Hovorka, D. and Gal, U., 2011. "Secondary design: A case of behavioral design science research," Journal of the Association for Information Systems, 12(10), p.662.

Grudin, J. 2006. "Why Personas Work: The Psychological Evidence," in The Persona Lifecycle: Keeping People in Mind Throughout Product Design, J. Pruitt and T. Adlin (eds.), San Francisco, CA, USA: Morgan Kaufman Publishers, pp. 642-663.

Hackos, J. T., and Redish, J. C. 1998. User and Task Analysis for Interface Design, Hoboken, NJ, USA: Wiley Publishing.

Hardwicke, N. 2017. "Practices in Juxtaposition: Tensions in social software appropriation projects", in Proceedings of the 28th Australasian Conference on Information Systems (ACIS 2017), Australasian Association for Information Systems, Hobart.

Herskovitz, S., and Crystal, M. 2010. "The essential brand persona: storytelling and branding," Journal of Business Strategy, (31:3), pp. 21-28. 
Hopcke, R.H. 1995. Persona: Where sacred meets profane. Shambhala Publications.

Hussain, M. and Skillicorn, D.B. 2008. "Persona-based identity management: A novel approach to privacy protection," In Proceedings of the 13th Nordic Workshop on Secure IT Systems (pp. 201212).

Jansen, A., Sulmon, N., Van Mechelen, M., Zaman, B., Vanattenhoven, J., and De Grooff, D. 2013. "Beyond the Familiar? Exploring Extreme Input in Brainstorms," in Proceedings of the 31st ACM Conference on Human Factors in Computing Systems, Paris, France, pp. 1347-1352.

Kantola, V., Tiitta, S., Mehto, K., and Kankainen, T. 2007. "Using Dramaturgical Methods to Gain More Dynamic User Understanding in User-Centered Design," in Proceedings of the 6th ACM Conference on Creativity \& Cognition, Washington, DC, USA, pp. 173-181.

Kumar, V., Loonam, J., Allen, J.P. and Sawyer, S. 2016. "Exploring enterprise social systems and organisational change: implementation in a digital age," Journal of Information Technology, vol. 31, no. 2, pp. 97-100.

Lindgren, A., Chen, F., Amdahl, P. and Chaikiat, P. 2007. "Using personas and scenarios as an interface design tool for advanced driver assistance systems," In International Conference on Universal Access in Human-Computer Interaction, (pp. 460-469).

Long, F. 2009. "Real or imaginary: The effectiveness of using personas in product design," In Proceedings of the Irish Ergonomics Society Annual Conference, (Vol. 14). Irish Ergonomics Society.

McGinity, R. and Salokangas, M. 2014. "Introduction: 'embedded research' as an approach into academia for emerging researchers," Management in Education, vol. 28, no. 1, pp. 3-5.

Mesgari, M., Okoli, C., and Ortiz de Guinea, A. 2015. "Affordance-based User Personas: A mixed-method Approach to Persona Development," in Proceedings of the 21st Americas Conference on Information Systems, Fajardo, Puerto Rico, pp. 1-17.

Mettler, T. and Winter, R. 2016. "Are business users social? A design experiment exploring information sharing in enterprise social systems", Journal of Information Technology, vol. 31, no. 2, pp. 101114 .

Miaskiewicz, T., and Kozar, K. A. 2011. "Personas and user-centered design: How can personas benefit product design processes?," Design Studies (32), pp. 417-430.

Mikkelson, N., and Lee, W. O. 2000. "Incorporating User Archetypes into Scenario-based Design," in Proceedings of the 9th Annual Usability Professionals' Association Conference, Asheville, NC, USA.

Mulder, S., and Yaar, Z. 2006. The User Is Always Right: A Practical Guide to Creating and Using Personas for the Web, Berkeley, CA, USA: New Riders.

Nielsen, L. 2013. "Personas," in Encyclopedia of Human-Computer Interaction, M. Soegaard and R.F. Dam (eds.), pp. 2039-2092.

O'Flaherty, B., Thornton, C., Pope, A., and Woodworth, S. 2013. "Capturing multi-stakeholder needs in Customer-Centric Cloud Service Design," in Proceedings of the 34th International Conference on Information Systems, Milan, Italy, pp. 1-15.

Pruitt, J., and Adlin, T. 2006. The Persona Lifecycle: Keeping People in Mind Throughout Product Design, San Francisco, CA, USA: Morgan Kaufman Publishers.

Pruitt, J. and Grudin, J. 2003. "Personas: practice and theory," In Proceedings of the 2003 conference on Designing for user experiences, (pp. 1-15). ACM.

Richter, A. and Riemer, K. 2013. "Malleable end-user software," Business \& Information Systems Engineering, 5(3), pp.195-197.

Riemer, K. and Johnston, R.B. 2014. "Rethinking the place of the artefact in IS using Heidegger's analysis of equipment", European Journal of Information Systems, vol. 23, no. 3, pp. 273-288.

Riemer, K. and Johnston, R.B. 2017. "Clarifying Ontological Inseparability With Heidegger's Analysis Of Equipment,” MIS Quarterly, 41(4). 
Schultze, U., Nardi, B., Rennecker, J., Stucky, S., and Hiltz, S. 2007. "Using Massively Multi-Member Online Worlds for Work and Education," in Proceedings of the 28th International Conference on Information Systems, paper 156.

Sissors, J. Z. 1966. “What Is a Market?,” Journal of Marketing, (30:3), pp. 17-21.

Turner, P., Turner, S., and Carruthers, L. 2014. “It's Not Interaction, It's Make Believe," in Proceedings of the 2014 European Conference on Cognitive Ergonomics, paper 22.

Upshaw, L. B. 1995. Building Brand Identity: A Strategy for Success in a Hostile Marketplace, Hoboken, NJ, USA: Wiley Publishing.

Visconti, L.M. 2010. "Ethnographic Case Study (ECS): Abductive modeling of ethnography and improving the relevance in business marketing research," Industrial Marketing Management, vol. 39, no. 1, pp. 25-39.

\section{Acknowledgements}

Natalie was an exceptional student, thinker and human being. Far too early, suddenly and unexpectedly Natalie passed away while this paper was under review. Natalie leaves a legacy of ideas and research that remains unfinished. This paper marks an important milestone in rethinking the ways in which malleable technologies can be introduced into organisational environments not prepared for such malleability. Hermeneutic personas play an integral part in this process. The Ripple Effect Group, who kindly gave permission for Natalie, as their embedded researcher, to use ethnographic accounts and the provided examples, and myself, as Natalie's supervisor, aim to continue this work. We will miss you, Nat.

\section{Copyright}

(C) 2018 Natalie Hardwicke \& Kai Riemer. This is an open-access article distributed under the terms of the Creative Commons Attribution-NonCommercial 3.0 Australia License, which permits noncommercial use, distribution, and reproduction in any medium, provided the original author and ACIS are credited. 